\title{
A\&L
}

ISSN 2709-0205

Vol 2 Issue 3 (2021)

https://doi.org/10.47855/jal9020-2021-3

\section{COVID-19 associated changes in the right departments of the heart in the elderly people}

\author{
Larysa A. Bodretska, Iryna S. Shapovalenko, Ivanna A. Antonyuk-Shcheglova, Olena V. Bondarenko, \\ Svitlana S. Naskalova, Valeri B. Shatilo
}

D. F. Chebotarev Institute of Gerontology NAMS of Ukraine, Kyiv, Ukraine

https:/doi.org/10.47855/jal9020-2021-3-3

Correspondence: naskalov@bigmir.net

Received: 29.09.2921; Accepted: 11.10.2021; Published: 18.10.2021

\begin{abstract}
Purpose of the work: to study the indicators characterizing heart lesions in elderly patients who had carried COVID-19.

Materials and methods: 86 patients older than 60 years old, were examined, of whom 56 (32 women and 24 men) who have carried COVID-19 between 3 and 6 months before the study, and 30 patients (12 men and 18 women) who did not have COVID - 19 in the anamnesis. The patients have been examined clinically, electro and echocardiography have been performed.

The results. Elderly patients during the post-covid period have complaints of shortness of breath, pain in the heart, swelling, coughing, weakness, which are more stable and intense than before the infection. Patients who have carried COVID-19 demonstrate the signs of a chronic pulmonary heart disease: increase in the size of a right ventricle and decrease of its contractile ability, increase in pressure in a pulmonary artery. Signs of a statistically significant moderate decrease of the contractility in the left ventricular were also identified.

Conclusions. The statistically significant changes in the right departments of the heart among the patients with carried COVID-19 with persistent symptoms after infection were defined. Patients who have carried COVID-19 but have no symptoms did not differ statistically from the control group.
\end{abstract}

Key words: COVID-19, old age, post- COVID period, right departments of the heart.

Thanks to the research conducted in 2020-2021 the understanding of the pathogenesis of COVID-19 has been changed from the respiratory infection to the systemic cell lesions that the angiotensin-converting enzyme receptors (ACE-2) are expressing. This allows to consider that COVID-19 is primarily a vascular infection, as evidenced in many studies, including Maccio, U. co-authored (2021), Rhodes, R. H. co-authored (2021), Zhang, J., Tecson K., co-authored (2021), Varga Z., Iba T., Connors J.M. co-authored (2020). The authors presented the proofs of the leading role of endothelium of small vessels in the damage of lungs, heart, kidneys, intestines and other organs in COVID-19 [1, 2, 3-5]. That is, the organ damage is a consequence of endothelium, and it is endothelial dysfunction that leads to hypercoagulation, vasoconstriction, organ ischemia and tissue edema due to the inflammation [6]. Thus, endothelium is one of the key syndromes in COVID-19 and the trigger of postCOVID syndrome $[7,5,8]$. Based on this, lung damage is accompanied by increased pressure in the pulmonary artery and an increase of the load on the right departments of the heart with the development of "right ventricular stress". In addition, COVID-19 is associated with hypercoagulable conditions with a high risk of thromboembolic changes in the branching of the pulmonary artery (PA), which has the pathogenesis of both systemic embolism and local thrombopathy of small vessels $[9,10]$. According to the research, COVID-19 has all the conditions for local thrombosis, formulated by Rudolf Virkhoviy: slowing of blood flow in the vascular bed of the lungs due to 
their paralytic expansion, hypercoagulation, endothelial damage, which reduces its thromboresistant properties. At PA of large branches there is a typical clinical picture and in most cases the corresponding treatment is carried out. As for recurrent thrombosis of small vessels of the pulmonary artery, in which the clinic is nonspecific, masked by the underlying disease, they are ignored and provoke further symptoms of shortness of breath, weakness, decreased tolerance to exercises, prolonged cough. For the elderly people, this is especially true due to their age and the risks of thrombosis caused by diseases of the cardiovascular system. Elderly patients are also characterized by the development of fibrosis in the tissues of organs, including and in the lungs, which significantly accelerates and intensifies after carried infection. Patients who have carried COVID-19 have residual symptoms for a long time, from 3 months to a year [11, 12,13]. Therefore, for today it is important to look for the markers of post- COVID heart disease, which may be key to the diagnosis and treatment of patients with postCOVID syndrome. The aim of our research was to study the indicators that characterize heart disease in elderly patients who have carried COVID-19.

\section{Materials and methods.}

86 patients were diagnosed with coronary heart disease; angina I - II FC, chronic heart failure of the I-II stages, NYHA of the II-III stages, in combination with arterial hypertension of the II stage and / or diabetes of the type II. Among them, there were 56 patients older than 60 years old (32 women and 24 men) who have carried COVID-19 in the period from 3 to 6 months before hospitalization in the cardiology department of the institute, the diagnosis was confirmed by RT-PCR test. The other 30 patients older than 60 years (mean age 68,2 $\pm 7,1$ years) had no history of COVID-19, antibodies M and G to SARS-COV2 by the results of enzyme-linked immunosorbent test performed immediately before hospitalization. Of the 56 patients who have carried COVID-19, 31 retained weakness, cough, and shortness of breath during exercises, which was a characteristic of a higher functional class according to NYHA than before the carried disease, edema, squeezing pain in the heart, without a clear dependence on physical exercises, increase and / or decrease in blood pressure (BP), inability to control blood pressure with drugs that they took for a long time before the disease, cardiac arrhythmias: tachycardia, bradycardia, extrasystolic arrhythmia. Patients have reported that after the carried infection, they had new complaints, and those that preceded the disease became of more persistent and intense character. No additional complaints have been reported in 25 patients after carried infection.

Patients underwent an echocardiography on the device "Xario SSA-660A" of the company "Toshiba" (Japan) in accordance with the standard methods using the sensor PST-30BT 3,0 MHz. The obtained parameters of the central hemodynamics, systolic and diastolic function, structural and functional state of the left and right ventricles and the mass of the myocardium of left ventricular (MLV) were determined using two-dimensional echocardiography with Doppler examination. There were measured end-systolic and end-diastolic size and volume of the left ventricle (ESD, EDD, ESV, EDV), the thickness of the interventricular septum (IVS), the left ventricle posterior wall (LVPW) in diastole, calculated the relative thickness of the left ventricle (RWT). The magnitude of ESV, EDV stroke volume (SV) and ejection fraction of LV were calculated by the Simpson method (in two mutually perpendicular projections), left ventricular myocardial mass (LVMI) by the Penn-convention formula (R.B. Devereux, N.Reichek). To assess the diastolic function of the heart there were studied the parameters of transmitral blood flow (TMF): the maximum rate of early (E) and late atrial (A) filling of the left ventricle, their ratio (E / A), the E-nive deceleration tme (DT), the time of isovolumic relaxation of the left ventricle (IVRT). We also studied the movement of the fibrous ring of the mitral valve (pulse tissue Doppler (TDI), and determined: the speed of early $(\mathrm{e} /)$ and late $(\mathrm{a} /)$ diastolic movement of the lateral and septal segments, the rate of systolic contraction (smkl, smks), calculated the ratio $\mathrm{E} / \mathrm{e} /$ to assess the end-diastolic pressure in the left ventricle. Measured the size of the right ventricle (RV), the amplitude of the tricuspid valve (TAPSE), the speed of early (e/) and late (a/) diastolic movement of the tricuspid valve (TV), the rate of systolic contraction of the TV (sTV). Pulmonary artery pressure (PAP) was calculated by the rate of maximal regurgitation on the tricuspid valve according to Bernoulli's formula, taking into account the central venous pressure, which is determined by the diameter and degree of collapse of the inferior vena cava. Ventricular-arterial coupling (VAC) for the right ventricle was calculated as the TAPSE / PAP ratio. [10], atrial volumes was measured by a modified Simpson method (VLA / VRA). The measurements were indexed to the body surface area calculated by the Dubois formula.

Electrocardiography (ECG) was performed on a Megacart device "Siemens", Germany software version 4.8.

Statistical data processing was performed using the modern packages of the application programs, in particular SPSS v.22, Statistica 10.0, MedCalc Statical Software v.11.5.0.0. Average indicators were determined 
using an analysis package in the system Office Excel 2007, Microsoft. The probability of the intergroup differences was assessed by Student's t-test for the unrelated values. The probability of multiple comparisons was assessed by the Post Hoc criterion - Bonferroni correction.

\section{Results.}

Examination of the patients revealed the signs of right ventricular overload among the symptomatic postCOVID patients. This is evidenced by the size of the right ventricle, increased pressure in the pulmonary artery, less contractile capacity of the pancreas: a decrease in TAPSE, the rate of systolic contraction of the TV (Tab. 1). In symptomatic post- COVID patients, there is also a statistically significant decrease in the contractile capacity of the left ventricle to moderate values.

Table 1

\section{Indicators of the structural and functional state of the heart in patients}

\begin{tabular}{|c|c|c|c|}
\hline & $\begin{array}{l}\text { Group of patients } \\
\text { without COVID-19 in } \\
\text { anamnesis, } n=30\end{array}$ & $\begin{array}{l}\text { Group } \\
\text { asymptomatic patients } \\
\text { with COVID-19 in } \\
\text { anamnesis, } \mathrm{n}=25\end{array}$ & $\begin{array}{l}\text { Group of patients with } \\
\text { COVID-19 in } \\
\text { anamnesis and the } \\
\text { presence of symptoms, } \\
\mathrm{n}=31\end{array}$ \\
\hline $\begin{array}{l}\text { RV (right } \\
\text { ventricle), cm }\end{array}$ & $3,87 \pm 0,12$ & $3,98 \pm 0,09$ & $4,34 \pm 0,04 * \#$ \\
\hline TAPSE, mm & $22,19 \pm 0,04$ & $23,11 \pm 0,07$ & $14,39 \pm 0,08 * \#$ \\
\hline $\mathrm{PAP}, \mathrm{mm} \mathrm{Hg}$ & $21,36 \pm 0,07$ & $23,74 \pm 0,05$ & $34,72 \pm 0,11 * \#$ \\
\hline TAPSE/ PAP & $1,11 \pm 0,03$ & $1,04 \pm 0,04$ & $0,42 \pm 0,03 * \#$ \\
\hline $\mathrm{iRA}, \mathrm{ml} / \mathrm{m}^{2}$ & $32,16 \pm 0,12$ & $33,22 \pm 0,09$ & $39,52 \pm 0,09 * \#$ \\
\hline $\mathrm{iLA}, \mathrm{ml} / \mathrm{m}^{2}$ & $34,27 \pm 0,10$ & $35,18 \pm 0,11$ & $34,26 \pm 0,09$ \\
\hline IVS, $\mathrm{cm}$ & $1,12 \pm 0,03$ & $1,13 \pm 0,02$ & $1,09 \pm 0,03$ \\
\hline LVPW, $\mathrm{cm}$ & $1,02 \pm 0,03$ & $1,07 \pm 0,04$ & $1,06 \pm 0,04$ \\
\hline RWT & $0,43 \pm 0,01$ & $0,45 \pm 0,02$ & $0,42 \pm 0,01$ \\
\hline $\mathrm{iESV}, \mathrm{ml} / \mathrm{m}^{2}$ & $17,23 \pm 0,05$ & $18,19 \pm 0,06$ & $21,76 \pm 0,07$ \\
\hline $\mathrm{iEDV}, \mathrm{ml} / \mathrm{m}^{2}$ & $44,83 \pm 0,11$ & $45,38 \pm 0,15$ & $48,76 \pm 0,09$ \\
\hline LVMI, $\mathrm{g} / \mathrm{m}^{2}$ & $107,27 \pm 0,21$ & $109,11 \pm 0,22$ & $112,42 \pm 0,13$ \\
\hline LVEF, \% & $58,47 \pm 0,22$ & $55,77 \pm 0,25$ & $46,34 \pm 0,19 * \#$ \\
\hline $\mathrm{CI}, \mathrm{ml} / \mathrm{m}^{2}$ & $27,12 \pm 0,08$ & $28,24 \pm 0,09$ & $31,47 \pm 0,15$ \\
\hline $\mathrm{S} \mathrm{mkl}, \mathrm{cm} / \mathrm{sec}$ & $7,71 \pm 0,04$ & $7,62 \pm 0,02$ & $7,34 \pm 0,03$ \\
\hline Smks, $\mathrm{cm} / \mathrm{sec}$ & $6,33 \pm 0,03$ & $6,51 \pm 0,01$ & $6,18 \pm 0,02$ \\
\hline $\mathrm{S}_{\mathrm{TV}}, \mathrm{cm} / \mathrm{sec}$ & $14,8 \pm 0,03$ & $13,9 \pm 0,04$ & $11,3 \pm 0,03 * \#$ \\
\hline
\end{tabular}

Patients with symptoms after carried COVID-19 had no ECG signs of acute pulmonary heart disease, but in 18 of them (58\%) there were changes which are the characteristic of hypertrophy and congestion of the right departments of the heart: deviation of the electrical axis of the heart to the right in $14(45 \%)$, the vertical position of the electrical axis in 4 (13\%), inversion of the T waves in diversion III, aVF, V1 and V2 in 11 (36\%), incomplete right bundle branch block in 9 (29\%), high-amplitude pointed teeth $\mathrm{P}$ waves in diversion III and aVF with a pronounced right atrial phase, the so-called P-pulmonale in $7(23 \%)$. The data obtained in the research coincide with the world and national studies of post- COVID patients [14, 15].

The detected changes among the symptomatic patients with carried COVID-19 definitely need treatment. Taking into account, that right departments of the heart have been mostly affected the with the formation of chronic pulmonary heart disease, it is advisable to use drugs of neurohumoral blockade of the renin-angiotensinaldosterone system $[15,16]$. As the patients have been already taking ACE inhibitors and beta-blockers before the treatment, it was advisable to add a mineralocorticoid receptor antagonist, spironolactone, which blocks the biological effects of aldosterone: sodium and water retention, potassium and magnesium loss, the development 
of generalized fibrosis, heart and vascular remodeling $[17,18]$. As endothelioprotective therapy, the most reasonable is the use of pentoxifylline, the properties of which correspond to the pathogenetic disorders in COVID-19. Especially important are the proven properties of the drug as for the protection of the endothelial cells from neutrophil damage, blockade of the release of lysosomal enzymes and elastase, improvement of the rheological properties of erythrocytes, inhibition of platelet aggregation, reduction of the chronic inflammation by blocking the synthesis of tumor necrosis factor. [9].

\section{Conclusions:}

1. Among the elderly patients during the post-COVID period the following complaints are observed as shortness of breath, pain in the heart, edema, cough, weakness, which are more persistent and intense than before the infection.

2. Patients who have carried COVID-19 and continue to feel the symptoms, demonstrate the signs of chronic pulmonary heart disease: an increase in the size of the right ventricle and a decrease of its contractility, increased pressure in the pulmonary artery. In addition, they demonstrate the signs of the statistically significant moderate decrease of the contractility of the left ventricle.

3. It is important to continue monitoring of the symptomatic post- COVID patients to resolve a number of issues, including how long the symptoms last, whether they need treatment, and which medicines of pathogenetic therapies may be effective..

Author Contributions: All authors participated equally in writing this article.

Conflicts of Interest: The authors declare no conflict of interest.

\section{Information about Authors:}

Larysa A. Bodretska - PhD (Medicine), Leading Researcher of the Department of Clinical Physiology and Pathology of Internal Organs; https://orcid.org/0000-0002-2154-9655

Iryna S. Shapovalenko - PhD (Medicine), Researcher of the Department of Clinical Physiology and Pathology of Internal Organs; https://orcid.org/0000-0003-4872-2021

Ivanna A. Antonyuk-Shcheglova - DSc (Medicine), Leading Researcher of the Department of Clinical Physiology and Pathology of Internal Organs; https://orcid.org/0000-0002-6122-826

Olena V. Bondarenko - PhD (Medicine), Senior Researcher of the Department of Clinical Physiologyand and Pathology of Internal Organs; https://orcid.org/0000-0002-2229-3719

Svitlana S. Naskalova - PhD (Medicine), Senior Researcher of the Department of Clinical Physiology and Pathology of Internal Organs; https://orcid.org/0000-0001-9518-2633

Valeri B. Shatilo - DSc (Medicine), Prof., Leading Researcher of the Department of Clinical Physiology and Pathology of Internal Organs, Deputy Director for Research; https://orcid.org/0000-0001-6420-000X 


\section{References}

1. Iba, T.; Connors, J. M.; Levy, J. H. The coagulopathy, endotheliopathy, and vasculitis of COVID-19. Inflamm Res 2020, 12, 1-9. https://dx.doi.org/10.1007\%2Fs00011-020-01401-6

2. Long, B.; Brady, W. J.; Koyfman, A.; Gottlieb, M. Cardiovascular complications in COVID-19. Am. J. Emerg. Med. 2020, 38, 7, 1504-1507. https://dx.doi.org/10.1016\%2Fj.ajem.2020.04.048

3. Rosa, G. M.; D'Agostino, A.; Giovinazzo, S.; La Malfa, G.; Fontanive, P. et al. Echocardiography of right ventricular-arterial coupling predicts survival of elderly patients with heart failure and reduced to mid-range ejection fraction. Monaldi Archives for Chest Disease, 2020, 90, 2. https://doi.org/10.4081/monaldi.2020.1269

4. $\quad$ Rhodes, R. H.; Love, G. L.; Lameira, F. D. S.; Sadough, M. S.; Fox, S. E. \& Vander Heide, R. S. Acute endotheliitis (type 3 hypersensitivity vasculitis) in ten COVID-19 autopsy brains. medRxiv 2021, 1-13. https://doi.org/10.1101/2021.01.16.21249632

5. Varga, Z.; Flammer, A. J.; Steiger, P.; Haberecker, M.; Andermatt, R. et al. Endothelial cell infection and endotheliitis in COVID-19. Lancet 2020,, 395, 10234, 1417-1418. https://doi.org/10.1016

6. Zhang, J.; Tecson, K. M. \& McCullough, P. A. Endothelial dysfunction contributes to COVID-19associated vascular inflammation and coagulopathy. Reviews in cardiovascular medicine 2020, 21, 3, 315-319. https://doi.org/10.31083/j.rcm.2020.03.126

7. Bernard, I.; Limonta, D.; Mahal, L. K. \& Hobman, T. C. Endothelium Infection and Dysregulation by SARS-CoV-2: Evidence and Caveats in COVID-19. Viruses 2020, 13, 1, 29. https://doi.org/10.3390/v13010029

8. Avdeev, S. N. Modern approaches to the diagnosis and treatment of pulmonary hypertension in patients with chronic obstructive pulmonary disease. Pulmonology 2009, 1, 90-101. (in Russian) https://doi.org/10.18093/0869-0189-2009-0-1-90-101

9. Lefer, A. N.; Lefer, D. J. Pharmacology of the endothelium in ischemia-reperfusion and circulatory shock. Ann. Rev. Pharmacol. Toxicol. 1993, 33, 71-90. https://doi.org/10.1146/annurev.pa.33.040193.000443

10. Maccio, U.; Zinkernagel, A. S.; Shambat, S. M.; Zeng, X.; Cathomas, G. et al. SARS-CoV-2 leads to a small vessel endotheliitis in the heart. EBioMedicine 2021, 63, 103182. https://doi.org/10.1016/j.ebiom.2020.103182

11. Gopinathannair, R.; Merchant, F.; Lakkireddy, D.; Etheridge, S. P.; Fiegovsky, S. et al. COVID-19 and cardiac arrhythmias: a global perspective on arrhythmia characteristics and management strategies. $J$ Interv Card Electrophysiol 2020, 10, 4, 1-8. https://doi.org/10.1007/s10840-020-00789-9

12. Klein, C. L.; Kohler, H.; Bittinger, F.; Wagner, M.; Hermanns, I. et al.Comparative studies on vascular endothelium in vitro. Pathobiol 1994, 62, 199-208. https://doi.org/10.1159/000163928

13. Gavrisyuk, V. K. Chronic cor pulmonale: mechanisms of pathogenesis and principles of therapy. Ukrainian pulmonological journal 2006, 4, 6-13. (in Russian)

14. Elias, P.; Poterucha, T. J.; Jain, S. S.; Sayer, G.; Raikhelkar, J. et al.The prognostic value of electrocardiogram at presentation to emergency department in patients with COVID-19. Mayo Clin Proc 2020, 95, 10, 2099-2109. https://dx.doi.org/10.1016\%2Fj.mayocp.2020.07.028

15. Zhang, J., Tecson, K. M., \& McCullough, P. A. Role of endothelial cell receptors in the context of SARS-CoV-2 infection (COVID-19). Proceedings 2021, 34, 2, 262-268. https://doi.org/10.1080/08998280.2021.1874231

16. Blagova, O. V., Kogan, E. A., Lutokhina, Y. A., Kukleva, A. D., Ainetdinova, D. H. et al. Subacute and chronic post-covid myoendocarditis: clinical presentation, role of coronavirus persistence and autoimmune mechanisms. Kardiologiia 2021, 61, 6, 11-27. (in Russian) https://doi.org/10.18087/cardio.2021.6.n1659

17. Dzyga, S. V.; Bakalets, O. V.; Begosh, N. B. COVID-19-related heart disease and features of electrocardiographic changes. Scientific and practical manual, Babinets, L. S. Ed. Osadtsa Yu. V.: Ternopil, 2021, 518-530. (in Ukrainian)

18. Napalkov, D. A. Mineralocorticoid receptor antagonists: a dubious past and a promising present. Consilium medicum 2015, 5, 63-67. (in Russian) 